\title{
Global Value Chains: A framework of Buyer-Supplier Management
}

\author{
Zhenming Sun \\ The O\&M Project Management, Sinoma SCC Project \\ $\mathrm{Na}$ Bi WU PO box 67105 \\ AL-HASSA 31928, Kingdom of Saudi Arabia \\ Tel: 96-6-532-076-880 E-mail: masseyjamiesun@hotmail.com
}

\begin{abstract}
Business clusters and global value chains (GVCs) command growing interest in some research disciplines. In the existing literature overwhelmingly focus on two niches: governance and upgrading. The detailed mechanisms of buyer-supplier relationship management tend to remain under-researched. This paper presents a framework base on the literature on the literature of International Marketing and Purchasing (IMP) group through a dyadic study of buyer-supplier relationship on GVC context.
\end{abstract}

Keywords: Global value chains, Business clusters, IMP, Buyer-supplier relationship

\section{Introduction}

In the recent two decades, business clusters have generated much excitement both academics and policy makers. A significant aspect of contemporary research concentration is the relationship between firms in the cluster and global buyers. The value chain approach offers a way for forward in analyzing such external linkages, connecting global market nodes (Gereffi, 1994). GVC has indicated how global linkages play a crucial role to enhance the ability of learning and innovation and access to high-tech knowledge (Humphrey and Schmitz, 2002a). Global value chains provide opportunities and challenges for business development in the developing countries. Generally speaking, the current research field of GVCs overwhelmingly concentrates on two basic niches: governance and upgrading. Such studies have provide a framework that is relevant on both the analysis and a depth understanding of how the third world fashion development strategies to climb up a higher value niches in the global economy. On the one hand, they can bring access to overseas markets, particularly developed world's market. On the other hand, entry to the value chain may be dependent on supplying low value products as low cost and a willingness to maintain at this level of activity.

Nevertheless, the existing literature tends of focus on a buyer or supplier perspective without considering the transaction between the two parties holistically. From the perspective of buyer-supplier dyad, the IMP (Industrial Marketing and Purchasing) group's studies are an exception that will be a theoretical framework to integrating the GVC literature to explore the buyer-supplier relationship.

This study paper goes beyond the existing tendency to discuss differences in global value chains using stereotypical typologies. These typologies typically differentiate 3-5 typed chains and draw generation about their characteristics of significance. One of significant weakness of the literature is that the role of global buyers' characteristics has been little explored beyond Gereffi's (1994) categorization of either buyer or driven commodity chains, with the respective forms of governance. In contrast, this study will disaggregate global buyers into a wider range of business types.

This paper is organized as follows. In the next section I will present a critical review on governance and upgrading in the GVC literature. Section 3 I outline a framework of analysis by adopting IMP literature into GVC context. Section 4 summarizes and concludes.

\section{Existing GVC literature: governance and upgrading}

Since the 1990s, the successful stories of the business clusters in the North, particularly in the Third Italy, has stimulated a attention to the potential provided by this model of industrial organization for the South. Business can be regarded as a major facilitating factor for a number of subsequent advantages, e.g. the emergence of a complicated network of clustered firm, and the appearance of trade association, the occurrence of organizations who sell to national or international markets. To capture the positive impacts of these elements on the competitiveness of clustered firms, the external economies are of significance in indicating the advantages of business clusters, but there is also a deliberate force work at work from local external economies (unplanned action) to consciously pursued joint action planned action 
(Schmitz, 1999). Based on an analytical point of view, the chain approach is helpful due to the fact the concentrates changes from manufacturing only to the multiple business activities conducted in the supply of products and services. The concentration of GVCs is on the essence of the relationship among the diversified factors linked to the value chains, and on the implications for growth (Humphrey and Schmitz, 2002b). To research these issues, 'governance' and 'upgrading' are central to focus.

The definition of 'governance' is firstly introduced by Gereffi (1994), defined as "authority and power relationship that determine how financial, material, and human resources are allocated and follow within a chain" (p.97). Governance is now central in GVC literature. Recent efforts on GVC governance have paid much attention rather than original contribution on non-hierarchical governance forms. A set of strategic parameters can be highlighted as characterizing governance types: 'what' or 'how' a product/service should be produced as well as 'when', 'how much' and even 'at the price'. Drawing upon these parameters, Humphrey and Schmitz (2000) distinguish three possible types of governance: network, quasi-hierarchy and hierarchy. In the context of 'network' governance, there are relationships that encourage enterprises with complementary which jointly establish the key parameters. Within this governance, the term is frequently used to denote some form of co-operation between 'equal'. Regarding other two types of governances, there are relationships characterized by a remark asymmetry of competence and power distribution between lead firms and subordinate firms in the chain. A quasi-hierarchy governance can be explained that the lead firms tend to specify what is to be produced, how it is to produced and how the firm performance is to be monitored. They argue this type of governance is common to exist in developing countries. In most of cases, the global buyers act as lead firms. More importantly, Humphrey and Schmitz (2000) also suggest that global buyers tend to disclose their core competencies to local suppliers.

The concept of upgrading has been often used by the literature on competitiveness (Kaplinsky \& Readman, 2001; Porter, 1990). Various recent studies explain the difference between the "high" and the "low road" to competitiveness with the capability of firms to upgrade (Humphrey \& Schmitz, 2000a; Kaplinsky \& Readman, 2001; Meyer-Stamer \& Seibel, 2001; Pietrobelli \& Rabellotti, 2002). All these studies share the same sense of urgency calling for sustained upgrading of business clusters in low economies. The majority of the literature discusses a hierarchy or upgrading path (e.g. Gereffi, 1999), which begins with the upgrading of process and product, then moves to functional upgrading and last of all, to competitiveness. In line with the present approach, Humphrey and Schmitz (2000b) discuss the prospects of upgrading with respect to the pattern of value chain governance. They conclude that insertion in a quasi-hierarchical chain offers very favourable conditions for process and product upgrading, but hinders functional upgrading; networks offer ideal upgrading conditions, but they are the least likely to occur for developing country producers.

The previous literature mainly focuses on two niches: governance and upgrading. The GVC literature on governance and upgrading has offered a framework that is not only relevant on the analysis of firms, but also to an understanding of how countries fashion development strategies to attempt to move themselves into relatively high value, sustainable niches in the global economy. However, a number of issues still need to address(Gereffi, 2001). According to the literature above, two significant research opportunities can be identified in this study.

- The scope of global buyers

- A holistic study on the management of buyer-supplier relationships

\subsection{The scope of global buyers}

With regard to the issue on the scope of global buyers, the existing literature has been explored beyond Gereffi's (1994) categorization of buyer-driven and producer-driven commodity chains, with their forms of governance. It is partly due to the unfinished work of global commodity chains and the angle of GCC governance. That is, the current literature on GVC and subsequent literature on GVC overwhelming concentrate on buyer-driven chains. Such literature usually focused attention on the powerful role that large retailers, such as Wal-Mart, and highly successful branded merchandisers, such as Nike, have come to play in the governance of global production and distribution (Sturgeon, 2006). In this study, I will identify such kind of global buyers as specialized buyers.

One of contribution of this study is to claim the heterogeneity in global value chains may significantly affect the way the relationship with local suppliers. As the discussed above, global buyers in this literature refer to giant discount chains, department stores, supermarkets, and brand marketer (so-called manufacturers without factories). The role of global buyers has been exaggerated due to this scope of global buyers. Sonobe and Otsuka (2006, p17) that "we do not believe, however, that superior production and management capacities were acquired by Asian entrepreneurs primarily from global buyers". In this respect, we completely concur with Humphrey and Schmitz (2004) that the firms which were most successful in functional upgrading and exporting new markets sere companies which had acquired their design and marketing experience in the national market. From the perspective of the theory of product lift cycle, one research analyzes that the process in which small local producers acquire production and product technologies and develop marketing capacities so as to grow large and eventually become able to export some of their products to 
advance countries, and these local producers learn a great deal of advance technological ideas and management know-how from foreign joint ventures (Sonobe \& Otsuka, 2006). Since this study does not cover product life cycle, I can not go further in this literature. In this study, I will extend the scope of global buyers (see figure 1):

(i) Specialized buyers, including to giant discount chains, department stores, supermarkets, and brand marketer, which have been intensively studied by the literature. They may embed into local supplier, an establishment of representative office in supplying county; or without any representatives in supplying county.

(ii) MNC buyers refer to subsidiaries of MNCs which purchase goods from the host county. None of studies makes explicit reference to this issue.

In this study, I will work on such two streams of global buyers as developed above (Figure 6). The impacts of two distinguishing types of global buyers on buyer-supplier relationship management also explore.

\subsection{A holistic study on the management of buyer-supplier relationships}

With reference to the role of global buyers, the empirical GVC literature (e.g. Humphrey and Schmitz, 2000) argue that captive or quasi-hierarchy governance is most common in developing countries. This type of governance is characterized by the significant dependence of small suppliers on large buyers for advanced production, methods, the design of products and marketing. Local producers have to face several obstacles when dealing with external sources of knowledge because of power asymmetries. The definition of quasi-hierarchy is confirmed by a number of other studies (e.g. Bazan and Navas-Aleman, 2004) showing global buyers are playing as 'lead firm'. The evidence presented is useful to single out the main regularities in GVC patterns of governance, but it has not given enough consideration on the role of producers in GVC context. That is, it cannot be assumed that the specific governance structure is the only determinant of the leaders' inherent ability or interest to help local producers to upgrading themselves. Some factors beyond governance structure are needed to further study. Nevertheless, and with a high dose of determinism, in the literature it argued that upgrading of firms in a value chain depending on governance pattern and power asymmetries among various actors within the chain. However, although Humphrey and Schmitz (2000) and Gereffi et al (2005) claim that a more dynamic approach suggests that chain governance is not given forever and may change, the most existing GVC literature in low income economies still tends to explore business upgrading activities in quasi-hierarchy governance. This partly leads to an overwhelming focus on the role of global buyers, with a lack of exploration on the side of local producers (suppliers). To some extent, the literature tends to focus on one side of the relationship, overwhelmingly emphasizing buyer perspective, without considering the transaction between the two parties holistically.

In sum, whatever the role played by leader (supporters or obstacles to local producers' upgrading), technology and knowledge transmission and their effectiveness often appear as exogenous to the local firms involved. That is, they would be either determined by the leaders strategies (i.e. GVC governance) or by other forces like for example, the degree of trust between buyers and suppliers, reliability (absorption capabilities of local producers). To what extent, according to the international management literature, the management of buyer-supplier relationship is critical for business success (Wilson, 1995). Regarding to the existing literature in GVC context whatever what kind of governance structures they are, buyer-supplier relationship is poorly explored by the GVC literature. For example, the level of the firm, firms relationship and the differences in buyer-supplier relationship and individual characteristics tend to be overshadowed. All these elements should be combined within a framework where firm-level dimensions as well as include in order to explain how within GVCs upgrading occur in the situations of involvement of both buyer and supplier.

Due to the fact that the theory of GVC governance and upgrading originally stem from the case studies, they tend to fail to address the issues on firm level. For example, the existing literature will fail to answer the question and the like as follows:

- Why do firms in the same industry and cluster demonstrate starkly different approaches to brining their products to global markets; or

- Under the same governance structure, why some firms can upgrade into global value chains; some are not able to do that? What factors beyond the governance context determine this?

When discussing heterogeneous resources, possessed by two parties in a buyer-supplier relationship, the issue of interaction becomes crucial. The parties interact in order to make the best out of both their own resource, and sustaining a good relationship between them. The IMP group developed since the end 1970s has provided a widely accepted way of holistic dyadic approach that will be followed in this study.

\section{IMP: A theoretical framework to integrate e GVC literature}

A total of 23 years ago, the first output form the International Marketing and Purchasing(IMP) group challenged some of the basic ideas of business marketing ( $\left.\mathrm{Ha}^{\circ} \mathrm{kansson}, 1982\right)$. The approach in that book has been adopted by many 
researchers and had led to a large number of research studies and doctoral theses and found its way into many books, managerial seminars and consultancy projects. The major benefits of the IMP approach interrelationships between the buyer and the supplier form the perspective of both parties when they interact. Thus this holistic dyadic approach has provided an extremely comprehensive descriptive account of the nature of business relationships.

The IMP approach contends the interactions between buyers and suppliers are shard by "environmental factors", which neither party to the exchange can directly control. This involves such aspects as market structure; dynamism; internationalization; channel position; and, social system (figure 6). The IMP approach contends, however, that, there are some elements of the interaction that buyers and suppliers can influence. Remarkably, one of the major benefits of this approach is its inclusiveness.

Framework can be an in-depth firm-level investigation of buyer-supplier dyad based on four cluster cases. Following the previous experience on IMP literature, two questionnaires can be produced: either for supplier or for buyer.

Three existing papers have summarized the factors influencing buyer-supplier relationships (Barnes et al, 2007; Power \& Reagan, 2007; Wilson, 1995). Wilson (1995) identifies 13 factors including successful buyer-supplier relationships, while another 13 factors also concluded by Power \& Regan (2007). Barnes et al (2007) produce a conceptual framework based on four relationships dimensions: legitimacy and compatibility; social relationships; economic bonds and shared values; and learning bonds. Based on the summary of influencing factors from these three papers as well as upgrading literature in GVC context, 22 items are identified as the main focus for this investigation of dyadic relationship in GVC context (see table 1). These 22 supporting items are classified into 2 groups of dimensions and 4 sub-dimensions. That, is, these four dimensions can be divided into two categories: invisible (including legitimacy and compatibility, social relations and share values) and visible variables (economic and learning bonds). The invisible variables may exist in the 'atmosphere', which never been explored by the GVC literature. The visible variables will contribute the upgrading issues on GVC literature from the perspective of the management of buyer-supplier relationship.

\section{Conclusion}

Global value chains represent a new form of industrial organization that is widely diffused in many industries across countries. Therefore, an analysis of its potential implications and consequences for firms in developing countries is of utmost relevance. However, recent research efforts in this direction have not fully clarified how global value chains foster innovation and learning processes in developing countries' firms. On the one hand, it has often been hinted that entering GVCs causes a sharp and automatic impact, either positive or negative, on local producers, in a deterministic fashion. On the other hand, the research agenda has shifted to the analysis of how local firms can join value chains, and on the influence of governance structures on upgrading.

This article provides theoretical and practical guidance on ways of managing business relationships from both the commercial and operational perspective of buyers and the suppliers. Existing literature tends of focus on a buyer or supplier perspective without considering the transaction between the two parties holistically. From the perspective of buyer-supplier dyad, the IMP (Industrial Marketing and Purchasing) group's studies are an exception that will be a theoretical framework to integrating the GVC literature to explore the buyer-supplier relationship.

\section{References}

Barnes, B. R., Naude, P. \& Michell, P. (2007). Perceptual gaps and similarities in buyer-seller dyadic relationships. Industrial Marketing Management, 36(5), 662-675.

Ford, D., McDowell, R. \& Tomkins, C. (1996). Relationship strategy, investments, and decision making. In D. Iacobucci (Ed.), Networks in marketing (pp. 144-176). CA: Sage.

Gereffi, G., Humphrey, J. \& Sturgeon, T. (2005),The governance of global value chains. Review of International Political Economy, 12(1), 78-104.

Kaplinsky, R. \& Readman, J. (2001). How can SME producers serve global markets and sustain income growth?. Mimeo, Brighton: University of Brighton and University of Sussex. http://www.ids.ac.uk/ids/global/valchn.html

$\mathrm{Ha}^{\circ}$ kansson, H. (Ed.). (1982). International Marketing and Purchasing of Industrial Goods: An Interaction Approach. Chichester.

Humphrey J. \& Schmitz H. (2000). Does Local Co-operation Matter? Evidence from Industrial Clusters in South Asia and Latin America. Oxford Development Studies. Vol. 28 (3),323-336.

Humphrey J., Schmitz H. (2002a). How does insertion in global value chains affect upgrading industrial clusters? Regional Studies, Vol. 36 (9).

Humphrey J., Schmitz H. (2002b). Developing Country Firms in the World Economy: Governance and Upgrading in Global Value Chains, INEF Report, No. 61, Duisburg: University of Duisburg. 
Gereffi G. (1994). The Organization of Buyer-Driven Global Commodity Chains: How U.S. Retailers Shape Overseas Production Networks, in G. Gereffi and M. Korzeniewicz (eds.),Commodity Chains and Global Capitalism, London: Praeger.

Meyer-Stamer J., M. C., Siebel S. (2001). "Improving upon Nature: Creating comparative advantage in Tile clusters in Italy, Spain and Brazil.", INEF Report, No. 54, Duisburg:University of Duisburg.

Pietrobelli C. \& Olarte B.T. (2002). Enterprise clusters and Industrial Districts in Colombia'sFashion Sector." European Planning Studies, 10(4), 541-562

Porter, M. (1990). The Competitive Advantage of Nations. Macmillan, London and Basingstoke.

Power, T. \& Reagan, W. (2007). Factors influencing successful buyer-seller relationships. Journal of business research. Vol. 60(12), 1234-1242.

Schmitz H. (1999a). "Increasing returns and collective efficiency", Cambridge Journal of

Economics, Vol. 23(4), 465-483.

Wilson, D. T. (1995). An integrated model of buyer-seller relationships. Academy of Marketing Science Journal, 23(4), $335-345$.

Table 1. 22 variables of 4 dimensions for exploring the buyer-supplier relationship in GVC context

\begin{tabular}{|l|l|}
\hline Dimensions & \multicolumn{1}{|c|}{ Variables } \\
\hline $\begin{array}{l}\text { legitimacy and } \\
\text { compatibility }\end{array}$ & Trust; Reliability; Mutuality; Brand image (quality); Reputation (quality) \\
\hline $\begin{array}{l}\text { Social relations } \\
\text { share values }\end{array}$ & Reloseness; Social circles; Communication; Friendship \\
\hline $\begin{array}{l}\text { economic and learning } \\
\text { bonds }\end{array}$ & $\begin{array}{l}\text { Staff exchange; Training; Co-design; Exchange of information; Joint } \\
\text { research; Quality control practices; Professional contacts; Integrated IT; } \\
\text { Ownership; Switching costs }\end{array}$ \\
\hline
\end{tabular}

Source: based on Barnes et al, (2007); Power \& Reagan, (2007); Wilson, (1995). 


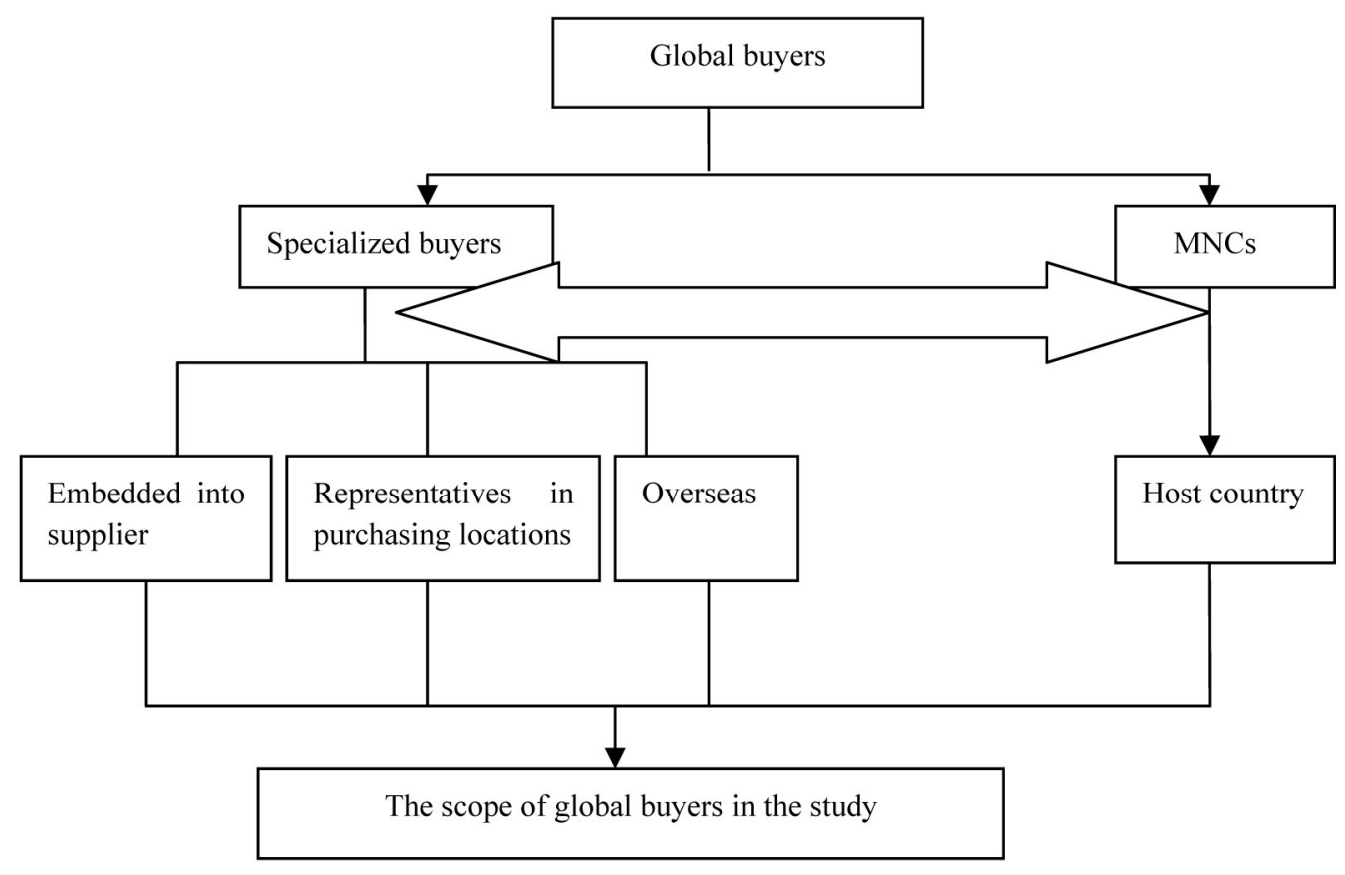

Figure 1. The scope of global buyers

Source: author's design

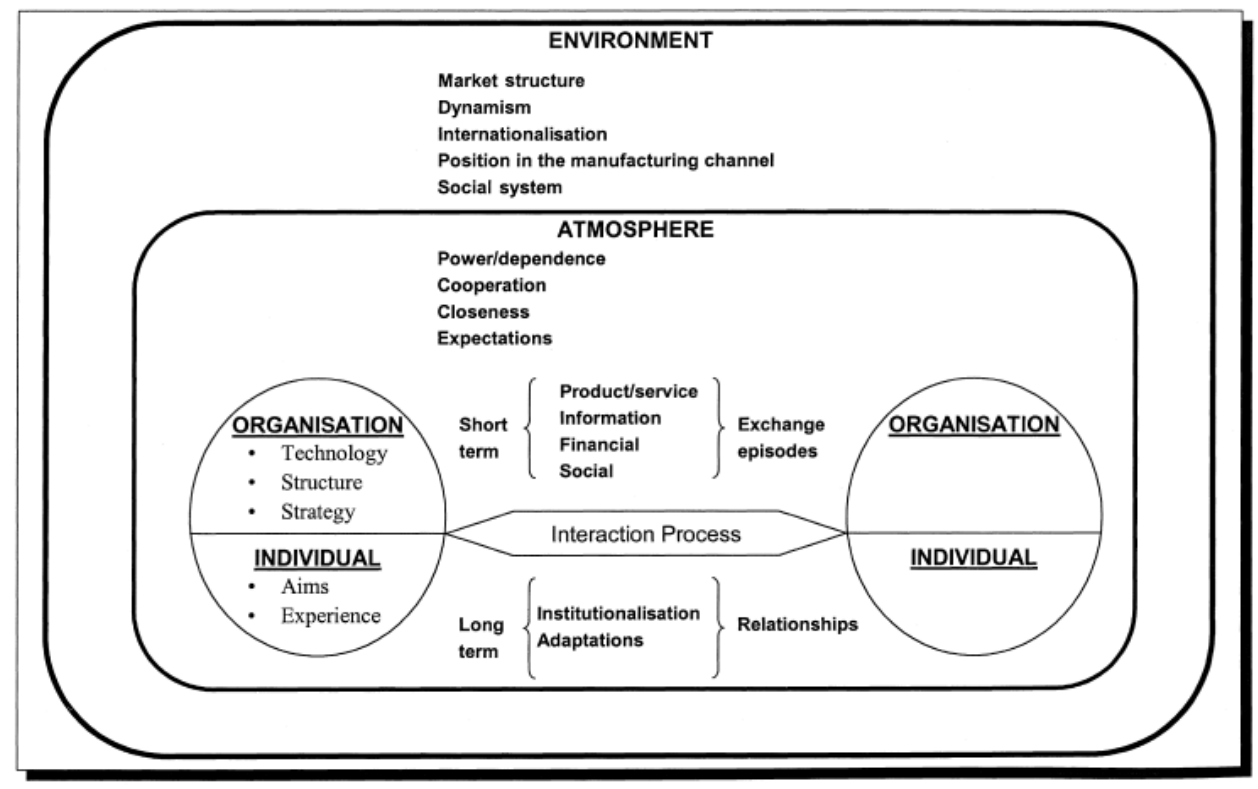

Figure 2. The IMP interaction model

Source: adapted from Ford, (1990) 